\title{
Sexual Function in Women With and Without Female Genital Mutilation in Reproductive Age in South of Iran
}

\section{Mahshid Bokaie}

Yazd University of Medical Science: Shahid Sadoughi University of Medical Sciences and Health Services

Samaneh Hatefi ( $\square$ samaneh.hatefi67@gmail.com)

Yazd University of Medical Science: Shahid Sadoughi University of Medical Sciences and Health Services https://orcid.org/0000-0002-6084-7436

\section{Shahnaz Mojahed}

Yazd University of Medical Science: Shahid Sadoughi University of Medical Sciences and Health Services

\section{Nasibeh Roozbeh}

Hormozgan University of Medical Sciences

\section{Research}

Keywords: Female genital mutilation, Female Circumcision, sexual dysfunction

Posted Date: March 1st, 2021

DOI: https://doi.org/10.21203/rs.3.rs-256453/v1

License: (9) This work is licensed under a Creative Commons Attribution 4.0 International License. Read Full License 


\section{Abstract}

Objectives: Female genital mutilation (FGM) is an important public health issue, especially in developing countries and it is still done in some parts of Iran. This study aimed to investigate the effect of FGM on the sexual function of women of reproductive age in Hormozgan province/IRAN.

Study design: This study is a descriptive-analytical case-control study that was conducted in 2020 on 209 married women of reproductive age (15-49) in rural areas of Minab and Sirik counties in Hormozgan province/IRAN.

Main outcome measures: The reliable and valid questionnaire FSFI for assessing female sexual function in the two groups was used after to obtain informed and voluntary consent from all participants and data with SPSS v: 16 software and with using descriptive/ Analytical statistics tests with a significant level of 0.05 were examined.

Results: There is a significant difference between mutilated and non-mutilated women in the total score of sexual function( $22.18 \pm 3.23$ versus $23.41 \pm 2.52$ respectively, $p=0.023)$ and the domains of lubrication( $3.04 \pm 0.62$ versus $3.3 \pm 0.53$ respectively, $P=0.000$ ), orgasm( $3.81 \pm 0.63$ versus $4.08 \pm 0.47$ respectively, $P=0.003)$, and sexual satisfaction( $5.09 \pm 0.1$ versus $5.37 \pm 0.87$ respectively, $P=0.017$ ) But in the domains of desire, arousal, and pain in the two groups was no significant difference(P-value $>0.05)$.

Conclusion: FGM maybe leads to sexual dysfunction. Although most women were reluctant to perform mutilation on their daughters, more educational Actions are suggested to educate women about the impact of female mutilation on their sexual function. Counseling programs are also recommended to improve the sexual function of mutilated women.

\section{Plain English Summary}

Female genital mutilation (FGM) is an important public health issue, especially in developing countries and it is still done in some parts of Iran. This study aimed to investigate the effect of FGM on the sexual function of women of reproductive age in Hormozgan province/IRAN. This study is a descriptiveanalytical case-control study that was conducted in 2020 on 209 married women of reproductive age (15-49) in rural areas of Minab and Sirik counties in Hormozgan province/IRAN. The reliable and valid questionnaire FSFI for assessing female sexual function in the two groups was used after to obtain informed and voluntary consent from all participants and data with SPSS v: 16 software and with using descriptive/ Analytical statistics tests with a significant level of 0.05 were examined. There is a significant difference between mutilated and non-mutilated women in the total score of sexual function( $22.18 \pm 3.23$ versus $23.41 \pm 2.52$ respectively, $p=0.023$ ) and the domains of lubrication(3.04 \pm 0.62 versus $3.3 \pm 0.53$ respectively, $P=0.000$ ), orgasm( $3.81 \pm 0.63$ versus $4.08 \pm 0.47$ respectively, $P=$ 0.003 ), and sexual satisfaction( $5.09 \pm 0.1$ versus $5.37 \pm 0.87$ respectively, $P=0.017$ ) But in the domains of desire, arousal, and pain in the two groups was no significant difference(P-value $>0.05)$. 
In conclusion; FGM maybe leads to sexual dysfunction. Although most women were reluctant to perform mutilation on their daughters, more educational Actions are suggested to educate women about the impact of female mutilation on their sexual function. Counseling programs are also recommended to improve the sexual function of mutilated women.

\section{Introduction}

Female genital mutilation (FGM) / Female Circumcision refers to any practice that intentionally and for non-medical purposes leads to amputation of all or part of the female external genitalia. It is an important issue in public health, especially in developing countries(1). This traditional and cultural action is dangerous. it leads to short-term complications include bleeding, sepsis, severe pain, and long-term complications include infertility, sexual dysfunction, and psychological complications(2). FGM is considered a form of violence against women and children and a violation of human rights because of its negative effects. It is classified into four categories: Type l: clitoridectomy (cutting part or all of the clitoris), Type II: excision (cutting the clitoris and labia minor with or without removing the labia major), Type III: Infibulation (reduction of the vaginal orifice by cutting the labia minor and/or the labia major), Type IV: which is used to describe all other harmful procedures to the genitalia without medical indication, such as piercing, incising, burning, etc.(3). Female circumcision has no health benefits for girls and women. Female circumcision can cause heavy bleeding and urinary problems, and later cysts, infections, as well as complications in childbirth and an increased risk of infant death. More than 200 million living girls and women today are circumcised in 30 countries in Africa, the Middle East and Asia, where it is concentrated. This operation is mostly performed on young girls from infancy to 15 years old(1). Girls feel helpless during circumcision because they have no choice and are forced to do so. Despite the effects of circumcision, some still support the practice(4). According to studies, damage to the clitoris following circumcision causes a woman to have less sexual arousal and not be easily sexually aroused, thus increasing their ability to remain a virgin before marriage and fidelity to their husbands after marriage(5). Positive experiences such as feelings of happiness, hope, and self-esteem usually follow an increase in social status after circumcision and negative psychological experiences such as shame if not circumcised, anxiety before circumcision and regret, sadness and anger when complications occur. It has been reported(6). In Iran, this practice is done as a tradition in some southern and western parts (7) and is rooted in their socio-cultural and religious beliefs, so that it is more prevalent in Sunni communities (8). FGM impairs sexual response by leaving scar tissue and adhesions and damage to the nerves of the clitoris, but sexual satisfaction is multidimensional and It depends on the amount of interest, the amount of time the sexual partner spends enjoying the woman, and the cultural context in which the man and woman live. Thus, physiological perspectives alone cannot explain the dyspareunia and decreased sexual satisfaction of mutilated women. Although the integrity of the clitoris and labia minor has a potential role in sexual pleasure, agreement and satisfaction are an important part of the sexual response and the sexual response of individuals is influenced by the interaction of neurophysiological and biochemical mechanisms and relationship dynamics and family and sociocultural issues. Mutilated women may be able to compensate for anatomical damage to their 
genitals by strengthening other erotic and sensitive areas of the body including the breasts, tongue, or vagina or their emotions and fantasies (limbic system)(3). Sexual satisfaction is one of the effective factors in reinforcing the family and its happiness and health. One of the most important causes of sexual dysfunction is the couple's disputes. On the contrary, sexual disorders also cause family disputes and dissatisfaction (9). The sexual function of mutilated women is influenced by several factors, including correct sexual knowledge and sufficient sexual arousal to achieve a satisfactory response (10). On the other hand, it can be hypothesized that as the severity of FGM increased, the complications also increased (11-13). Dan Reisel et al. in their study concluded that Although it is clear that FGM can cause devastating short and long term health complications for girls and women, there is an extraordinary scarcity of high quality research to inform clinical practice (14). Female sexual function is important because sexual health represents the foundation of individual health (12). Biglu et al. (2016) Acknowledged the decline in female sexual function after mutilation (15), however, Catania et al. (2007) reported no difference in the sexual function of mutilated and non-mutilated women (16). Rouzi et al. (2018) observed a significant difference between the severity of mutilation and female sexual dysfunction (13), While Yassin et al. (2018) observed that the decrease in sexual desire and satisfaction and dyspareunia in the mutilated group was significantly greater than the non-mutilated group, but this difference was not significant in different degrees of mutilation (17). Due to the contradictory results on the effect of FGM on their sexual function, the present study was conducted to investigate the sexual function of mutilated and non-mutilated women of reproductive age in Hormozgan province.

\section{Methods}

This study is a descriptive-analytical case study that was conducted in 2020 on married reproductive age women (15-49 years) in rural areas of Minab and Sirik counties in Hormozgan province, which is the southernmost part of Iran, including Kohestak, Shahid Mardan, Bandzark, Bemani, and Noband who referred to health centers and their mutilation status was confirmed by examination by a midwife. These villages were culturally similar and differed only in the prevalence of female mutilation.

\subsection{Sample size}

In this formula

$$
n_{A}=n_{B}=\frac{\left(Z_{1-\alpha / 2}+Z_{1-\beta}\right)^{2}\left[p_{A}\left(1-p_{A}\right)+p_{3}\left(1-p_{B}\right)\right]}{\left(p_{A}-p_{B}\right)^{2}}
$$

$\mathrm{n}$ is the required sample size, $\alpha$ is a first type error and $1-\beta$ is the test power, which in our study is $1-\beta=0.9$ and $\alpha=0.05$ have been considered. According to the study of Ismail et al. That sexual dysfunction was reported to be 0.83 in the case group and 0.64 in the control group, by inserting numbers in the sample volume determination formula, at least 109 people were obtained in each group (18).

\subsection{Inclusion \& exclusion criteria}

Inclusion criteria included formal marriage, any type of mutilation in the mutilated group, and no mutilation in the other group, age 15-49 years. Exclusion criteria including women with chronic physical/ 
mental disease, pregnancy, and childbirth in the last 6 months, death or separation from her spouse, people who have not had any sexual activity in the past 6 months.

\subsection{Female Sexual Function Index(FSFI) Questionnaire:}

FSFI questionnaire designed by Rosen et al. In 2000 and contains 19 questions. This standard questionnaire measures six domains of female sexual functioning included Sexual desire, arousal, lubrication, orgasm, satisfaction, and pain over the past 4 weeks. Questions 1 and 2 of the questionnaire (sexual desire), questions 3-4-5 and 6 (sexual arousal), questions 7-8-9 and 10 (lubrication), questions 1112 and 13 (orgasm), questions - 14-15 And 16 (sexual satisfaction), questions 17-18 and 19 (related to pain). A score of 1-5 was given for sexual desire questions, a score of 0-5 for sexual arousal, lubrication, pain, orgasm, and a score of 1-5 or 0 for sexual satisfaction questions. The reliability of the scale and subscales was obtained by calculating the Cronbach's alpha coefficient, which was calculated for the whole population of 0.70 and above, which indicates the reliability of this instrument. The maximum score is 36 and the minimum is 2 and a higher score indicates the optimal sexual function (19). In their study, Mohammadi et al. examined the reliability and validity of the FSFI questionnaire. The cut-off point appropriate to the whole scale for the diagnosis of sexual dysfunction was determined 28. According to this study, the sensitivity of the instrument was $82 \%$ and its specificity was $83 \%$. The Persian version of FSFI is a reliable and valid instrument for assessing female sexual function and can be used as a screening instrument(20). This questionnaire was completed by the participants in the presence of the midwife to answer the ambiguities.

\section{Results}

This study was performed on 213 women aged 15-49 years living in rural areas of Hormozgan province who met the inclusion criteria. Fourteen of these women were excluded from the study Because of the exclusion criteria. The women were studied in two groups: mutilated $(n=110)$ and non-mutilated $(n=99)$. A midwife confirmed that $100 \%$ of the mutilated women had undergone type I mutilation. The mean age in mutilated women was $31.44 \pm 5.76$ and in non-mutilated women was $29.76 \pm 6.5$ with no statistically significant difference $(p=0.053)$. The mean age of the spouse in mutilated women was $34.44 \pm 5.99$ and in non-mutilated women was $32.71 \pm 6.88$ which there was no statistically significant difference $(p=$ 0.056). There was no significant difference in the level of education of women in the two groups $(P=$ 0.076). The frequency distribution of other demographic characteristics of the studied units is shown in Table 1. 
Table 1

Comparision of the frequency distribution of demographic

\begin{tabular}{|c|c|c|c|c|c|c|}
\hline & & $\begin{array}{l}\text { Frequency } \\
\mathrm{N}\end{array}$ & $(\%)$ & $\begin{array}{l}\text { Frequency } \\
\mathrm{N}\end{array}$ & $(\%)$ & P valve \\
\hline \multirow{4}{*}{$\begin{array}{l}\text { Female } \\
\text { education }\end{array}$} & Primary & 27 & 24.54 & 12 & 12.12 & 0.076 \\
\hline & Secondary & 66 & 60 & 63 & 63.63 & \\
\hline & Academic & 17 & 15.46 & 24 & 24.24 & \\
\hline & total & 110 & 100 & 99 & 100 & \\
\hline \multirow[t]{4}{*}{ spouse' education } & Primary & 20 & 18.18 & 17 & 17.17 & 0.136 \\
\hline & Secondary & 72 & 65.46 & 55 & 55.55 & \\
\hline & Academic & 18 & 16.36 & 27 & 27.27 & \\
\hline & total & 110 & 100 & 99 & 100 & \\
\hline \multirow[t]{3}{*}{ Mother's education } & Primary & 49 & 44.55 & 52 & 52.52 & 0.071 \\
\hline & Secondary & 61 & 55.45 & 47 & 47.48 & \\
\hline & total & 110 & 100 & 99 & 100 & \\
\hline \multirow[t]{3}{*}{ Father's education } & Primary & 47 & 42.72 & 55 & 55.55 & 0.122 \\
\hline & Secondary & 63 & 57.26 & 44 & 44.45 & \\
\hline & total & 110 & 100 & 99 & 100 & \\
\hline \multirow{3}{*}{$\begin{array}{l}\text { Female } \\
\text { occupation }\end{array}$} & Housekeeper & 103 & 93.64 & 90 & 90.9 & 0.315 \\
\hline & Occupy & 7 & 6.36 & 9 & 9.09 & \\
\hline & total & 110 & 100 & 99 & 100 & \\
\hline \multirow[t]{3}{*}{ spouse's occupation } & Employee & 18 & 16.36 & 21 & 21.21 & 0.235 \\
\hline & Worker & 92 & 83.64 & 78 & 78.78 & \\
\hline & total & 110 & 100 & 99 & 100 & \\
\hline Religion & Shiite & 109 & 99.09 & 99 & 100 & 0.526 \\
\hline \multirow[t]{2}{*}{ (Muslim) } & Sunnite & 1 & 0.91 & 0 & 0 & \\
\hline & total & 110 & 100 & 99 & 100 & \\
\hline
\end{tabular}




\begin{tabular}{|lllllll|}
\hline & & Frequency & (\%) & Frequency & (\%) & P valve \\
& & N & & N & & \\
\hline The mode of Delivery & NVD & 71 & 64.55 & 52 & 52.52 & 0.138 \\
& C/S & 27 & 24.55 & 28 & 28.28 & \\
& Nullipara & 12 & 10.9 & 19 & 19.19 & \\
& total & 110 & 100 & 99 & 100 & \\
\hline
\end{tabular}

It was also found that 58 mutilated women (52.3\%)underestimated the impact of mutilation on their sexual function and 35 mutilated women $(31.5 \%)$ found the effect of mutilation on the sexual function to be moderate and 17 mutilated women (16.2\%) found the effect of mutilation on the sexual function to be high. This study showed that the score of sexual function in mutilated women $(22.18 \pm 3.23)$ was significantly lower than non-mutilated women $(23.41 \pm 2.52)(P=0.023)$. It was also found that the score of sexual function in the domains of lubrication, orgasm, and sexual satisfaction in mutilated women is significantly lower than non-mutilated women $(P<0.05)$ but there is a significant difference between the score of female sexual function in the domains of desire and arousal $(p>0.05)$ (Table2).

Table 2

The Female sexual function index scores in the study groups

\begin{tabular}{|llll|}
\hline Variables & \multicolumn{2}{c}{ Mean (SD) } & P-valve \\
\cline { 2 - 3 } & Mutilated & Non-mutilated & \\
\hline Desire & $3.66 \pm 0.78$ & $3.81 \pm 0.78$ & 0.265 \\
\hline Arousal & $4.19 \pm 0.98$ & $4.49 \pm 1.23$ & 0.098 \\
\hline Lubrication & $3.04 \pm 0.62$ & $3.3 \pm 0.53$ & 0.000 \\
\hline Orgasm & $3.81 \pm 0.63$ & $4.08 \pm 0.47$ & 0.003 \\
\hline Pain & $2.38 \pm 1.09$ & $2.35 \pm 1.11$ & 0.892 \\
\hline Satisfaction & $5.09 \pm 0.1$ & $5.37 \pm 0.87$ & 0.017 \\
\hline Total & $22.18 \pm 3.23$ & $23.41 \pm 2.52$ & 0.023 \\
\hline
\end{tabular}

\section{Discussion}

This study aimed to investigate the sexual function of mutilated and non-mutilated women of reproductive age in Hormozgan province. The results of data analysis of this study show a significant difference in the overall score of female sexual function in the mutilated and non-mutilated groups, but the results show that both groups of women are below the cut-off point. The finding also shows that the 
score of sexual function in the domains of lubrication, orgasm, and sexual satisfaction in the mutilated group is lower than the non-mutilated group and this difference is significant in the two groups ( $P$-value < 0.05 ) but the score of sexual function in the domains of desire, arousal and pain in the mutilated and non-mutilated groups are not significantly different (P-value >0.05). Ismail et al. (2017) in their study showed that the frequency of intercourses in mutilated women is less than non-mutilated women (18). The present study also shows the difference between the two groups, but this difference is not significant. Mahmoud et al. (2016) in their study showed that the overall score of sexual function of mutilated women is less than the score of sexual function of non-mutilated women (14.3 $\pm 5.93 \mathrm{vs} .25 .9$ $\pm 3.44)$ (21). Biglu et al. (2016) in a study concluded that the total score of the FSFI and all domain scores in non-mutilated women is lower than non-mutilated women (25.4 \pm 3.34 vs. $17.9 \pm 5.39)$ (15). The present study is in line with this study in reducing the total score of sexual function and the domains of lubrication, orgasm, and sexual satisfaction in the mutilated group. Daneshkhah et al. (2017) in their study concluded that female sexual function in various domains including desire, arousal, lubrication, orgasm, satisfaction, and sexual pain is significantly affected by mutilation So that the score of all domains in the mutilated group was less than the non-mutilated group (18.25 \pm 6.32 vs. $23.90 \pm 7.12)(8)$. The present study on reducing the total score of sexual function in the domains of lubrication, orgasm, and sexual satisfaction in the mutilated group is consistent with this study. Alsibiani et al. (2010) concluded that there was no significant difference in the mean desire scores $(3.6 \pm 1.1$ in the mutilated group versus $3.7 \pm 1.2$ in the control group) or sexual pain ( $3.5 \pm 1$ in the mutilated group versus $3.8 \pm 1.1$ in the control group) between the two groups (P-value $>0.05)$; however, there is a statistically significant difference in the mean scores of arousal, lubrication, orgasm, and sexual satisfaction as well as the total score of sexual function between the two groups $(21.4 \pm 4.4$ vs. $23.5 \pm 5)(P-v a l u e=0 / 009)(22)$. The present study is also consistent with this study on the lack of significant differences in the domains of sexual desire and pain in the two groups. It is also consistent with this study regarding the existence of significant differences in the domains of lubrication, orgasm, and satisfaction in the two groups, but is not consistent with this study in the domain of arousal reduction in the mutilated group. Ismail et al. In their study concluded that the mean scores of all domains of FSFI and its total score in both types I and II FGM are significantly lower than the control group except the desire score in FGM/C type I. $(20.26 \pm 6.9$ and18.64 \pm 7.5 vs. $23.34 \pm 8.1)$ (P-value $=0 / 000)(18)$. The present study on the significant difference in sexual function score and sexual function score in the domains of lubrication, orgasm, and sexual satisfaction in the two groups is consistent with this study. In their study, Catania et al. (2007) found that mutilated women had higher scores in the domains of desire, arousal, orgasm, and satisfaction than nonmutilated women (16); But this study was confounded by the unmatched control group consisting mainly of western women. In our study, we tried to eliminate this confounder by recruiting control women from equivalent cultural backgrounds with matching residence and education. our study is inconsistent with this study because mutilated women have lower scores in the domains of desire, arousal, orgasm, and sexual satisfaction than non-mutilated women, Although the difference in desire and arousal between the two groups is not significant. In a review of 17 studies, Berg et al. (2010) concluded that although intact genital tissue such as clitoris and labia minor is essential for sexual response, sexual response is multidimensional and also depend on affection, the time the partner takes to please the woman and must 
be considered within the context in which a woman and her partner live. It is a complex interaction of neurophysiological and biochemical mechanisms and influenced by relationship dynamics and family and sociocultural issues. Berg et al. Also stated that women with FGM may have an ability to compensate for anatomical damage to their genital tissue through enhancement of other sensory and erotic areas, or emotions and fantasy (limbic system) and sexual sensations in women with FGM may be maintained by a shift of the point of maximal sexual stimulation from the clitoris and/or labia to other areas of the body(their breasts, tongue or vagina), which can be attributed to the lack of significant differences in sexual desire between the two groups in our study. our study found that mutilated women reported difficulty reaching orgasm so that, their spouse must make great efforts to stimulate their sexual response and reach them orgasm (3). In line with previous studies, it was found that mothers played a significant role in female mutilation and fathers had almost no role in this regard so that in our study more than $95 \%(\mathrm{~N}=105)$ of girls underwent mutilation at the suggestion of their mother that this is a custom(8). Fortunately, the present study found that most mothers (67\%) are reluctant to have their daughters mutilated. The role of education in the intention to perform mutilation is specified (23). In line with previous studies, it was found that education may be the apparent reason for the decrease in the incidence of FGM. As the parents' educational status increased, the tendency to mutilate their female children decreased (24); so more educational actions are suggested to make women aware of the impact of FGM on their sexual function. One of the strengths of the present study is the use of a valid FSFI instrument to assess women's sexual function. One of the limitations of the present study was that due to the higher prevalence of type I FGM in the study area, it was not possible to reach women with severe FGM, which of course could have a greater impact on their sexual function.

\section{Conclusion}

FGM leads to sexual dysfunction. Although most women were reluctant to perform FGM on their daughters, more educational measures are suggested to make women aware of the impact of FGM on their sexual function. Counseling programs are also recommended to improve the sexual function of mutilated women.

\section{List Of Abbreviations}

Female Sexual Function Index (FSFI)

Statistical Package for Social Science (SPSS)

Female Genital Mutilation (FGM)

\section{Declarations}

\section{Declarations:}


The informed and voluntary consent was obtained from all participants. MB participated in the design of the study the manuscript. SH carried out the Collecting data and drafted the manuscript. NR performed the statistical analysis. ShM conceived of the study, and participated in its coordination. All authors read and approved the final manuscript.

\section{Conflict of interest:}

None

\section{Funding:}

This article is the result of a master's thesis in midwifery counseling. The authors would like to thank the participants and the University Research Vice Chancellor for financial support.

\section{Ethical:}

This study is based on the MSc thesis and the ethical committee (code: IR.SSU. REC.1398.090) of Shahid Sadoughi University of Medical Sciences was approved it.

\section{Data sharing and collaboration:}

There are no linked research data sets for this paper. Due to the sensitive nature of the questions asked in this study, survey respondents were assured that raw data would remain confidential and would not be shared.

\section{Acknowledgments:}

The authors would like to thank the participants and the University Research Vice Chancellor for financial support.

\section{References}

1. WorldHealthOrganization. fact sheet on female genital mutilation 2020. Available from: http://www.who.int/mediacentre/factsheets/fs241/en/.

2. Berg RC, Underland V, Odgaard-Jensen J, Fretheim A, Vist GE. Effects of female genital cutting on physical health outcomes: a systematic review and meta-analysis. BMJ open. 2014;4(11):e006316.

3. Berg RC, Denison E, Fretheim A. NIPH Systematic Reviews. Psychological, Social and Sexual Consequences of Female Genital Mutilation/Cutting (FGM/C): A Systematic Review of Quantitative Studies. Oslo, Norway: Knowledge Centre for the Health Services at The Norwegian Institute of Public Health (NIPH) Copyright (c)2010 by The Norwegian Institute of Public Health (NIPH). 2010.

4. Obiora OL, Maree JE, Nkosi-Mafutha NG. Experiences of young women who underwent female genital mutilation/cutting. Journal of Clinical Nursing. 2020;29(21-22):4104-15. 
5. Odo AN, Dibia SIC, Nwagu EN, Umoke M, Umoke PCI. Towards characterization of Female Genital Mutilation (FGM) in rural Nigeria. African Health Sciences. 2020;20(4):1968-78.

6. Omigbodun O, Bella-Awusah T, Groleau D, Abdulmalik J, Emma-Echiegu N, Adedokun B, et al. Perceptions of the psychological experiences surrounding female genital mutilation/cutting (FGM/C) among the Izzi in Southeast Nigeria. Transcultural Psychiatry. 2020;57(1):212-27.

7. Bokaie M KZ, Roozbeh N, Mojahed S. Female genital mutilation in Southern Iran. African Health Sciences. 2020;20(2):666-7.

8. Daneshkhah F, Allahverdipour H, Jahangiri L, Andreeva T. Sexual Function, Mental Well-being and Quality of Life among Kurdish Circumcised Women in Iran. Iranian journal of public health. 2017;46(9):1265-74.

9. Nori M, Shirzad M, Soltaninejad A. Prediction of Marital Satisfaction on the Quality of Life of Students of Allameh Tabatabai and Imam Hussein (AS) Universities. Iranian Journal of Health Education and Health Promotion. 2016;3(4):360-9.

10. Thabet SM, Thabet AS. Defective sexuality and female circumcision: the cause and the possible management. The journal of obstetrics and gynaecology research. 2003;29(1):12-9.

11. Andersson SH, Rymer J, Joyce DW, Momoh C, Gayle CM. Sexual quality of life in women who have undergone female genital mutilation: a case-control study. BJOG : an international journal of obstetrics and gynaecology. 2012;119(13):1606-11.

12. Buggio L, Facchin F, Chiappa L, Barbara G, Brambilla M, Vercellini P. Psychosexual Consequences of Female Genital Mutilation and the Impact of Reconstructive Surgery: A Narrative Review. Health equity. 2019;3(1):36-46.

13. Rouzi AA, Berg RC, Sahly N, Alkafy S, Alzaban F, Abduljabbar H. Effects of female genital mutilation/cutting on the sexual function of Sudanese women: a cross-sectional study. American journal of obstetrics and gynecology. 2017;217(1):62.e1-.e6.

14. Reisel D, Creighton SM. Long term health consequences of Female Genital Mutilation (FGM). Maturitas. 2015;80(1):48-51.

15. Biglu MH, Farnam A, Abotalebi P, Biglu S, Ghavami M. Effect of female genital mutilation/cutting on sexual functions. Sexual \& reproductive healthcare : official journal of the Swedish Association of Midwives. 2016;10:3-8.

16. Catania L, Abdulcadir O, Puppo V, Verde JB, Abdulcadir J, Abdulcadir D. Pleasure and orgasm in women with Female Genital Mutilation/Cutting (FGM/C). The journal of sexual medicine. 2007;4(6):1666-78.

17. Yassin K, Idris HA, Ali AA. Characteristics of female sexual dysfunctions and obstetric complications related to female genital mutilation in Omdurman maternity hospital, Sudan. Reproductive health. 2018;15(1):7.

18. Ismail SA, Abbas AM, Habib D, Morsy H, Saleh MA, Bahloul M. Effect of female genital mutilation/cutting; types I and II on sexual function: case-controlled study. Reproductive health. 2017;14(1):108. 
19. Rosen CB JH, S. Leiblum, C. Meston, R. Shabsigh, D. Ferguson, R. D'Agostino, R. 2000;26 (2):191-208. The Female Sexual Function Index (FSFI): a multidimensional self-report instrument for the assessment of female sexual function. Journal of sex \& marital therapy. 2000;26:191-208.

20. Mohammadi K HM, Faghihzadeh S. . The female sexual function index (FSFI): validation of the Iranian version. Payesh (Health Monitor) 2008;7(3)::269-78.

21. Mahmoud M. Effect of female genital mutilation on female sexual function, Alexandria, Egypt. Alexandria Journal of Medicine. 2015;61.

22. Alsibiani SA, Rouzi AA. Sexual function in women with female genital mutilation. Fertility and sterility. 2010;93(3):722-4.

23. Shahnaz Mojahed MS, Mahshid Bokaie, Ali Dehghani;11(4):. Evaluation of the effect of group training on beliefs and intention to do female genital mutilation in pregnant women referring to Qeshm/Iran comprehensive health centers. J Adv Pharm Edu Res 2021(4):1-6 (In press).

24. Orji E, Babalola A. Correlates of female genital mutilation and its impact on safe motherhood. Journal of the Turkish German Gynecology Association. 2006;7:319-24. 